\title{
Thermal Behavior and Flammability of Polyurethanes Based on Diphenylmethane-4,4'-diisocyanate and Incorporating 3-Chloro-1,2-propanediol in the Main Chain
}

\author{
Krzysztof PIELICHOWSKI ${ }^{\dagger}$ \\ Department of Chemistry, Technical University, \\ ul. Warszawska 24, 31-155 Kraków, Poland
}

(Received March 10, 1997)

\begin{abstract}
For a series of diphenylmethane-4,4'-diisocyanate (MDI) and 3-chloro-1,2-propanediol (CPDO), propanediol (PDO), or polyoxyethyleneoxidediane (POEOD) based polyurethanes degradation profiles and flammability were investigated by thermogravimetric analysis (TGA) alone or coupled with Fourier transform infra-red spectroscopy (FT-IR), differential scanning calorimetry (DSC), and oxygen index (OI) method. It was found that several correlations between the thermal parameters, such as initial decomposition temperature (IDT) or mass loss at given conversion degree, and oxygen index (or oxygen concentration) occur, thus making it possible to predict the thermal behavior of modificated polyurethanes on the basis of thermogravimetric data only. TGA with FT-IR proved to be a valuable extension of methods of thermal analysis commonly used to provide continuous monitoring of the IR spectra of evolving volatiles as well as quantitative analysis of gases produced during the decomposition process.
\end{abstract}

KEY WORDS Thermal Properties / Flammability / Modificated Polyurethanes /

Flammability of polymers is an old and unsolved problem. Apart from the novel antipyrene compositions there is still a need for reliable methods for testing the flammability of polymeric materials. This requires the development of laboratory methods which are minimum time-, labor-, and material consuming and can provide insight into the mechanism of the degradation/combustion process. Yet the problem of flammability and its measurement has never been of such interest as it is today since the introduction (or imminent introduction) of stringent legislation.

Among many methods for the investigation of flammability so far, such as Factory Mutual fire test apparatus, ${ }^{1}$ the cone calorimeter, ${ }^{2}$ and oxygen index method, ${ }^{3}$ there are also other approaches, based on thermoanalytical techniques (TA). ${ }^{4-7}$

Among them, the thermogravimetric analysis (TGA) is probably one of the most commonly used methods. This fast reproducible bench scale method is employed through its display of the thermal degradation profile of minute samples. Several thermal degradation parameters (e.g., DTG-max-temperature or char residue), describing the course of decomposition, are used for the evaluation of overall flammability. TGA can be used to decipher whether flame-retarding process occurs in the vapor or condensed phase. Differential scanning calorimetry (DSC) is mainly used to observe changes in the polymers prior to and during the decomposition. Less commonly used techniques include thermomechanical analysis (TMA) and dynamic mechanical analysis (DMA). They measure the mechanical properties of the polymeric materials before and after flame retardation modification.

Another effective technique is the use of thermogravimetry coupled to IR spectroscopy (TGA/FT-IR). An important feature of this method is that the evolved gases can be identified in sequential order and a specific gas

$\dagger$ Tel/Fax: + 48-12-6342425. may be associated with a specific weight loss. In contrast to pyrolysis GC, in which all the gases produced by heating to a given temperature are separated and analyzed as a batch. TGA/FT-IR offers the great advantage of sequentially identyfying gases thus making it possible to follow reaction pathway in the vapor phase.

The aim of the present work is to study thermal degradation and flammability of several modificated polyurethanes, and to prove correlations between parameters for both processes.

\section{EXPERIMENTAL}

\section{Materials}

Polyurethanes used in the course of this work were prepared according to the method in ref 6. 3-Chloro-1,2propanediol (Aldrich) and polyoxyethyleneoxidediane (POEOD, ICSO Kędzierzyn-Koźle) were used as received.

The description of the samples is given in Table I.

\section{Thermogravimetric Analysis}

Thermogravimetric analysis was performed on a Derivatograph-C (MOM, Hungary) thermal analyzer,

Table I. Sample features

\begin{tabular}{ccccc}
\hline \multirow{2}{*}{ Sample } & 3-Chloro-1,2-propanediol & 1,2-Propanediol & POEOD \\
\cline { 2 - 3 } & mol\% & mol\% & mol\% \\
\hline 1 & 0 & 80 & 20 \\
2 & 20 & 80 & 0 \\
3 & 20 & 60 & 20 \\
4 & 20 & 40 & 40 \\
5 & 20 & 20 & 60 \\
6 & 40 & 40 & 20 \\
7 & 40 & 20 & 40 \\
8 & 60 & 20 & 20 \\
9 & 80 & 20 & 0 \\
10 & 80 & 0 & 20 \\
11 & 100 & 0 & 0 \\
\hline
\end{tabular}


Table II. Sample features

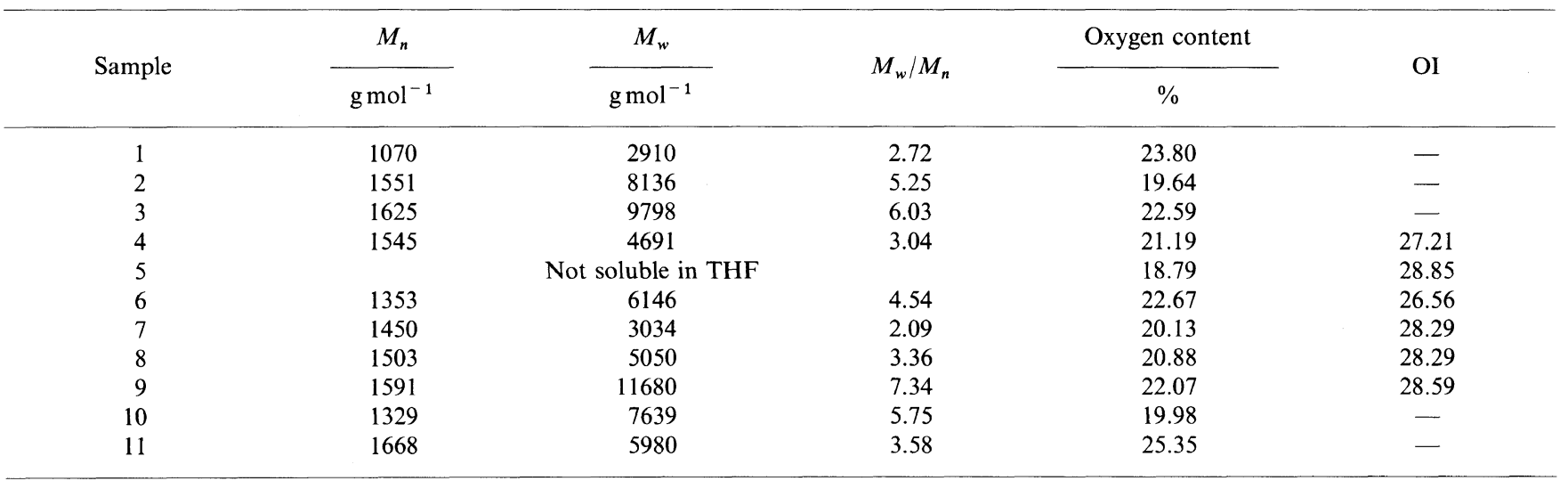

Table III. Results of the thermogravimetric analysis of samples $1-11$

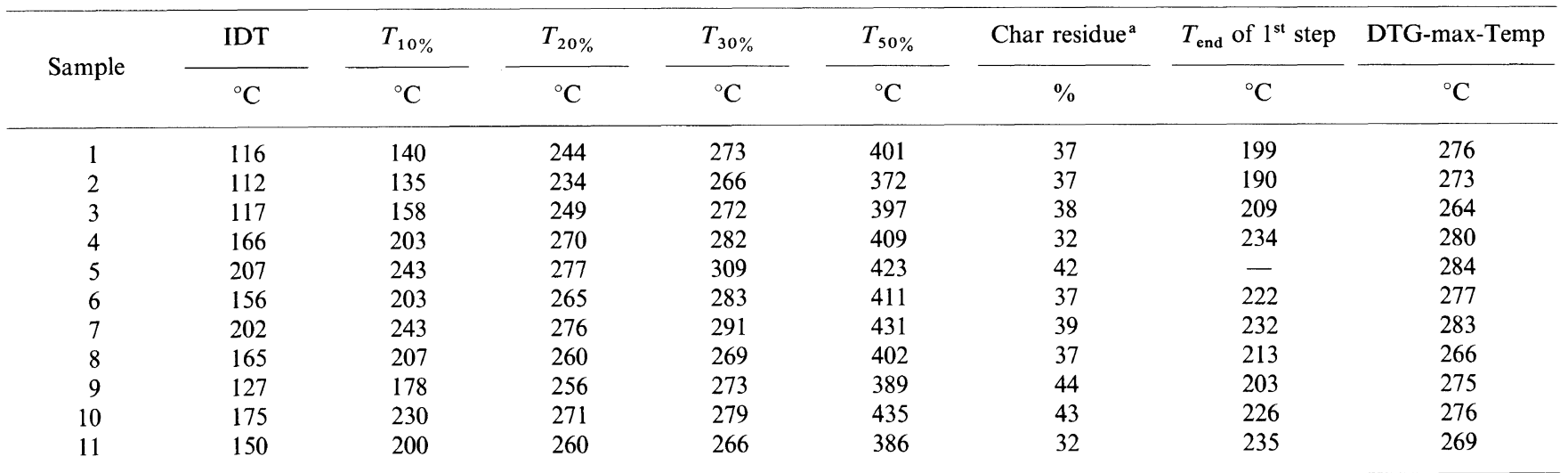

${ }^{a}$ Char residue is remaining sample mass at $500^{\circ} \mathrm{C}$, given in $\%$.

operated in a dynamic mode at a heating rate of 10 $\mathrm{K} \mathrm{min}^{-1}$. The conditions were: sample weight, $\sim 10 \mathrm{mg}$; atmosphere, air; temperature range, $25-500^{\circ} \mathrm{C}$; reference material, $\mathrm{Al}_{2} \mathrm{O}_{3}$.

Thermogravimetric Analysis Coupled with Fourier Transform Infra-Red Spectroscopy

Thermogravimetric analysis with Fourier transform infra-red spectroscopy was carried out using a PerkinElmer 7 thermogravimetric analyser (heating rate, 50 $\mathrm{K} \mathrm{min}{ }^{-1}$; sample weight, $\sim 15 \mathrm{mg}$; nitrogen flow, 50 $\mathrm{cm}^{3} \mathrm{~min}^{-1}$ ) and a Perkin-Elmer 1725X FT-IR spectrometer. The thermogravimetric analyser and spectrometer were suitably coupled to enable the passage of evolved products from the furnace to the gas cell over a short path, to minimise secondary reaction or condensation on cell walls. Experimental conditions were chosen to ensure that the condensable products form asubmicron aerosol mist with two advantages: (i) the particles follow gas stream lines, thus minimizing condensation, and (ii) the particles produce little scattering in mid IR, so the condensable products can be analyzed online in FT-IR cell.

\section{Differential Scanning Calorimetry}

For DSC measurement a Netzsch DSC 200, operated in a dynamic mode, was used. Sample of app. $4 \mathrm{mg}$ weight was placed in sealed aluminium pan. The heating rate of $10 \mathrm{~K} \mathrm{~min}^{-1}$ was the best choice to ensure high resolution of the DSC curves. Prior to use the calorimeter was carefully calibrated with an indium standard; an empty aluminium pan was used as reference.

\section{Oxygen Index}

Oxygen index (OI) is the minimum volume concentration of oxygen in an oxygen-nitrogen atmosphere necessary to initiate and support a flame for $>3 \mathrm{~min}$. Measurements were performed on a standard flammability test apparatus, according to the procedure in ref 3 .

\section{Gel Permeation Chromatography}

Molecular weight was determined by GPC performed at $25^{\circ} \mathrm{C}$ on a Knauer 64 GPC System with a refractometric detector, with two PL-Gel columns. Tetrahydrofuran (THF) was used as the eluant at a flow rate of $0.8 \mathrm{~cm}^{3} \mathrm{~min}^{-1}$, and sample concentration was $5 \mathrm{mg} \mathrm{cm}^{-3}$. Polystyrene standarts (Waters) were used to construct a calibration curve. GPC data were processed using a CHROMA program to calculate average molecular weights, $M_{n}$ and $M_{w}$, as well as polydispersity, $M_{w} / M_{n}$. These data are summarized in Table II.

\section{Elemental Analysis}

$\mathrm{C}, \mathrm{H}, \mathrm{N}$ analysis was done using a Perkin-Elmer 240 elemental analyzer. $\mathrm{Cl}$ content was determined by Schoeninger method. ${ }^{8}$ Oxygen content (OC) was calculated as the difference between $100(\%)$ and sum of $\mathrm{C}, \mathrm{H}, \mathrm{N}$, and $\mathrm{Cl}(\%)$. 


\section{RESULTS AND DISCUSSION}

Thermal stability of the samples was investigated by thermogravimetric analysis, operated in the non-isothermal mode. The results in Table III show that the degradation profiles are characterized through different thermal parameters.

The initial decomposition temperature (IDT) was from 112 to $207^{\circ} \mathrm{C}$, being highest for sample 7 with $40 \%$ of chloropropanediol. Other temperatures and char residue amount also considerably differ, indicating the influence of chemical structure on the degradation pathway. Generally, at elevated temperature and in an atmosphere of air macroradicals react with oxygen to form hydroperoxides which are unstable and break down rapidly to form more free radicals. According to the Bolland-Gee mechanism a macroradical is initially formed which then react with oxygen to form a peroxy radical. The peroxy radicals are reactive and abstract hydrogen atom by an intra- or intermolecular process to generate a hydroperoxide group and another macroradical site. The hydroperoxides then decompose into alkoxy and hydroxy radicals, which in turn can react with polymer backbone giving water molecules (Scheme 1) ${ }^{9}$ :

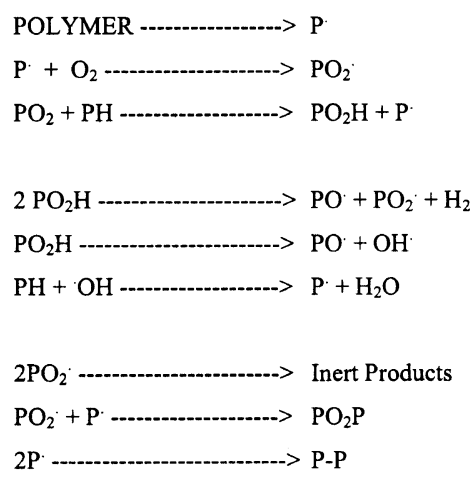

$$
\begin{aligned}
& \text { (Initiation) } \\
& \text { (Chain Branching) } \\
& \text { (Termination) }
\end{aligned}
$$

Scheme 1.

The course of thermal decomposition depends not only on the basic chemical structure of a polymer, but also many internal and external factors at other microstructural levels. The most important internal factors $\operatorname{are}^{10}$ :

(i ) energy state of the initial material and products of the reaction;

(ii) mobility of structural elements of the space lattice, which depends on the geometry of the lattice, charge of the elements, etc.;

(iii) activation energy, which depends on the nature of the reacting substances and region of conversion;

(iv) dispersion state of initial materials, which influences the surface energy and mobility of lattice elements;

(v) lattice defects;

(vi) irregularities in the polymer chain (internal unsaturations, branches, oxidation structures, etc.);

(vii) structural similarities (or dissimilarities) of the initial materials and products.

The most important external factors are:

(i ) temperature, decisive for the mobility of lattice elements and influence not only the course of chemical

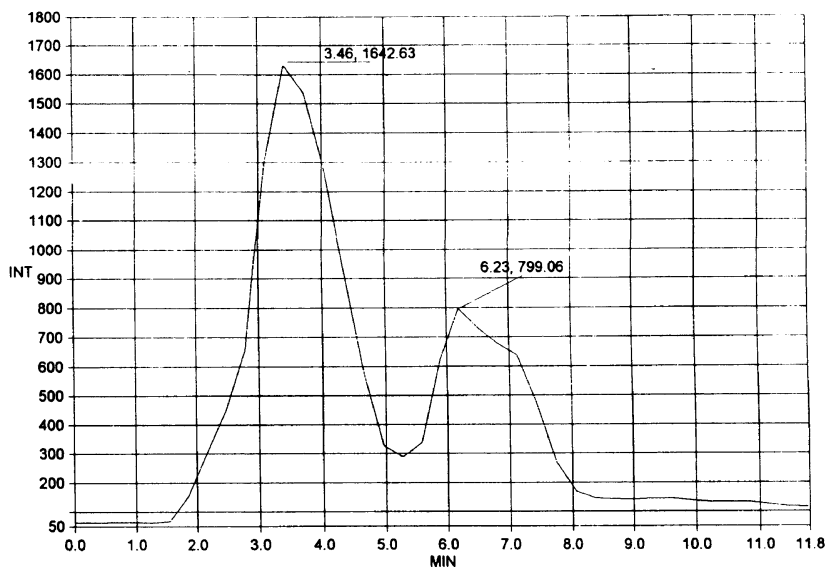

Figure 1. Gram-Schmidt chromatogram of sample 7.

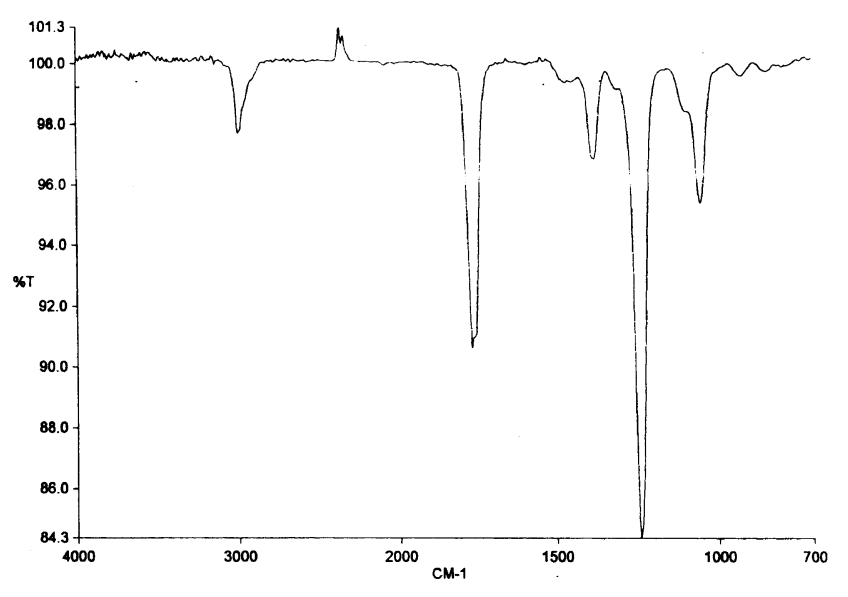

Figure 2. FT-IR spectrum of sample 7 after $3.46 \mathrm{~min}$.

reaction, but also space and surface diffusions;

(ii) the duration of a process;

(iii) pressure and composition of the gas phase;

(iv) catalysts, the role of which can be played by impurities in the initial materials or products of degradation.

Bearing in mind that several of these factors cannot be separated one from another, it seems justifiable that one is using certain global thermal parameters (e.g., char residue) as a measure of flammability which itself is a complex phenomena consisting of many partial reactions.

The two main degradation steps of modificated polyurethanes can be analysed by TGA/FT-IR. First, evolved gas profiles calculated on the basis of the Gram-Schmidt orthogonalization yield information concerning the way of volatiles emission (Figure 1).

Analysis of the FT-IR spectrum after 3.46 min (maximum of the first peak) (depicted in Figure 2) reveals that there are several characteristic absorption bands $\left[3000 \mathrm{~cm}^{-1}\right.$ (saturated $\left.\mathrm{C}-\mathrm{H}\right), 2400 \mathrm{~cm}^{-1}\left(\mathrm{CO}_{2}\right), 1760$ $\mathrm{cm}^{-1}(\mathrm{C}=\mathrm{O}), 1400 \mathrm{~cm}^{-1}$ (OH bending), and 1250/1070 $\mathrm{cm}^{-1}$ (C-O stretching)] present in the system.

Analogous analysis of the second hump indicates mainly evolution of $\mathrm{CO}_{2}$, with a strong absorption band at $2364 \mathrm{~cm}^{-1}$ (Figure 3).

Change in absorption bands intensivity vs, time, i.e., kinetics of evolution or formation of species, can be 


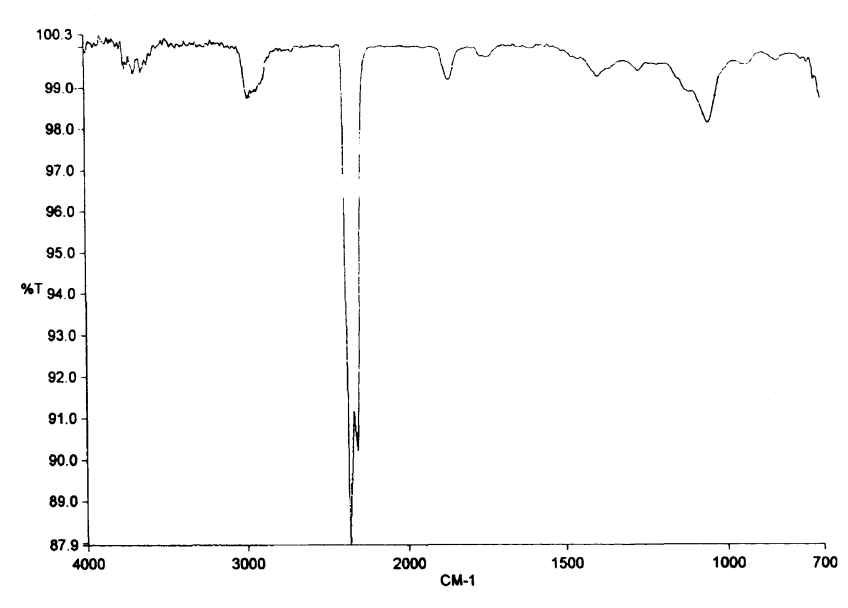

Figure 3. FT-IR spectrum of sample 7 after $6.23 \mathrm{~min}$.

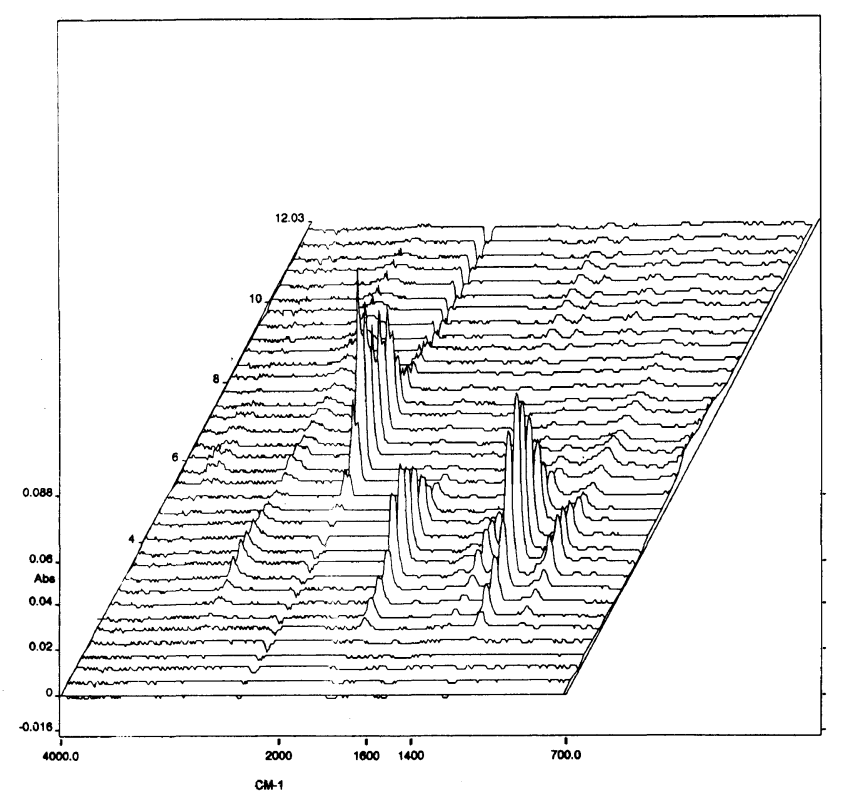

Figure 4. Stacked plots of FT-IR spectra of sample 7 from 0 to $12 \mathrm{~min}$. followed by stacked plot, as shown in Figure 4.

By TG/FT-IR measurements the degradation reaction is shown to proceed mainly via formation of primary amine and olefin, with possible propagation leading to the secondary amine (Scheme 2).

I. Formation of primary amine and olefin

$$
\mathrm{R}(\mathrm{NH}) \stackrel{\text { II }}{\mathrm{C}}-\underset{\mathrm{H}}{\mathrm{O}}-\underset{\mathrm{H}}{\mathrm{CH}}-\mathrm{CH}_{2} \mathrm{R}^{\prime} \longrightarrow \mathrm{RNH}_{2}+\mathrm{CO}_{2}+\mathrm{R}^{\prime} \mathrm{CH}=\mathrm{CH}_{2}
$$

II. Formation of secondary amine

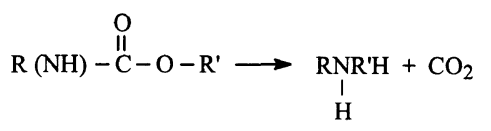

Scheme 2.

From DSC results, information on combustion process is available. The degradation predominates in areas of highest urethane group concentration, i.e., hard segment domains. ${ }^{11}$ The reactions proceed in the soft segment regions. Several typical DSC traces are shown in Figure 5.

As polymer degradation progresses, DSC curves become complicated, but heat of combustion $\left(\Delta H_{\mathrm{c}}\right)$ could be obtained. The physicochemical meaning of this quantity for fire retardancy prediction remains questionable since for some polymers there is no definite correlation between $\Delta H_{\mathrm{c}}$ and flammability. The same applies to $T_{\text {onset }}$ of decomposition. As presented in Figure 5 the $T_{\text {onset }}$ determination is rather complicated. Oxygen index data in Table II, show that the highest OI can be attributed to samples 5 and 9, with amount of chloropropanediol of 20 and $80 \%$, respectively. Several correlations between OI (or oxygen content, OC) and the thermal parameters from thermogravimetric analysis have been found. Hence, there is a linear relationship between OI (or OC) and: IDT (Figure 6), temp. of 30\% mass loss

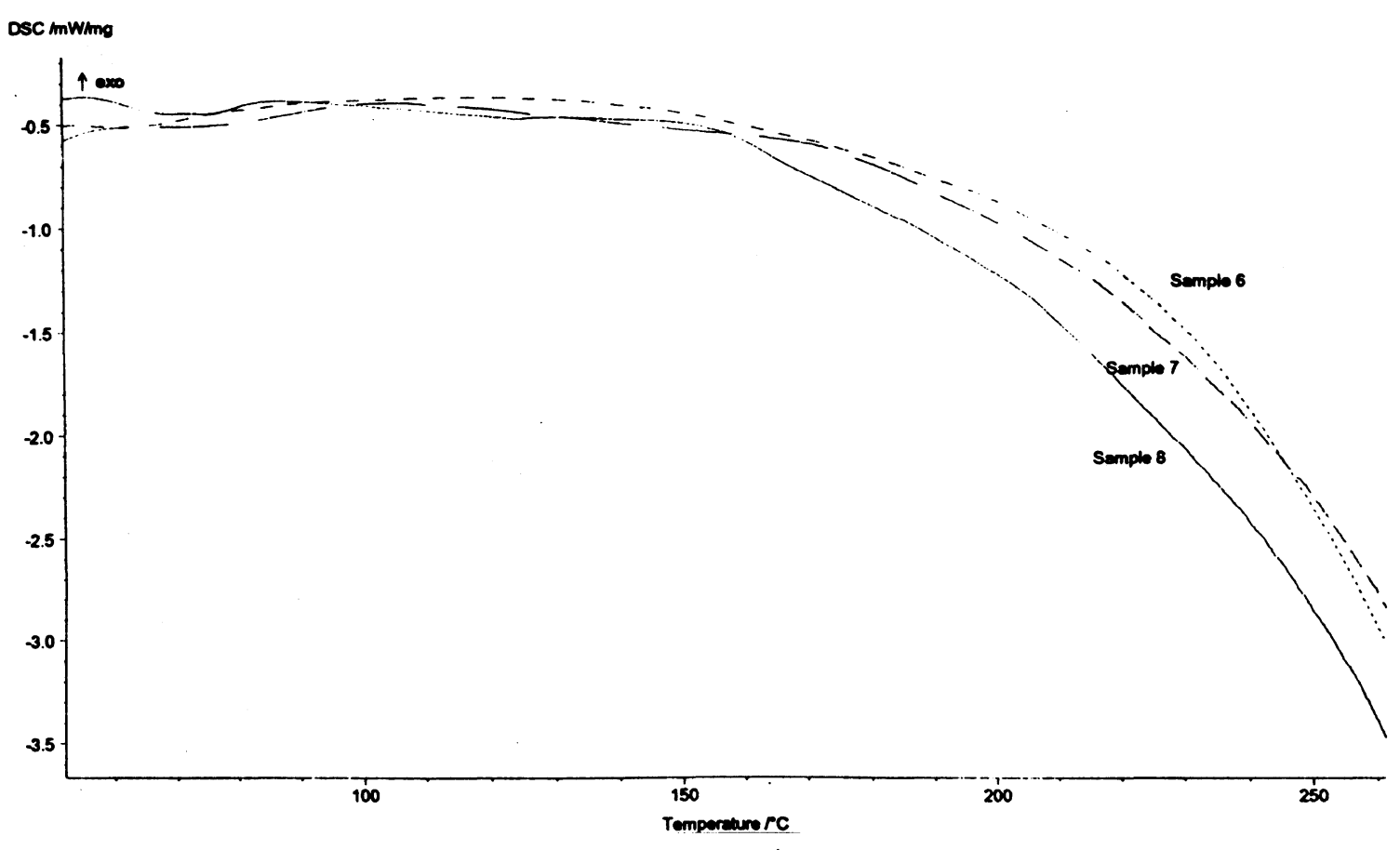

Figure 5. DSC curves at $10 \mathrm{~K} \mathrm{~min}^{-1}$ of samples 6,7 , and 8 . 


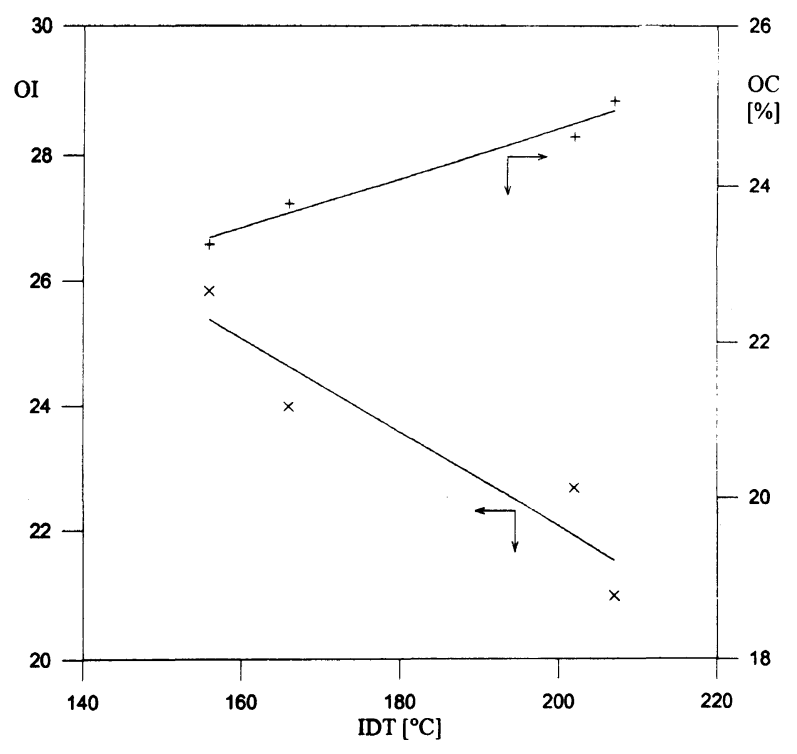

Figure 6. OI and OC $v s$. IDT.

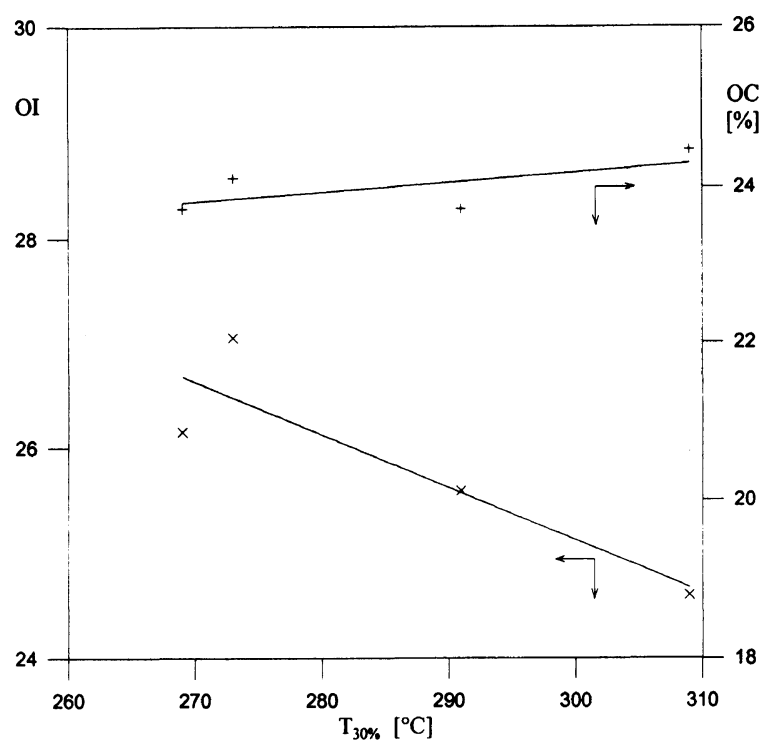

Figure 7. $\mathrm{OI}$ and $\mathrm{OC} v s . T_{30 \%}$.

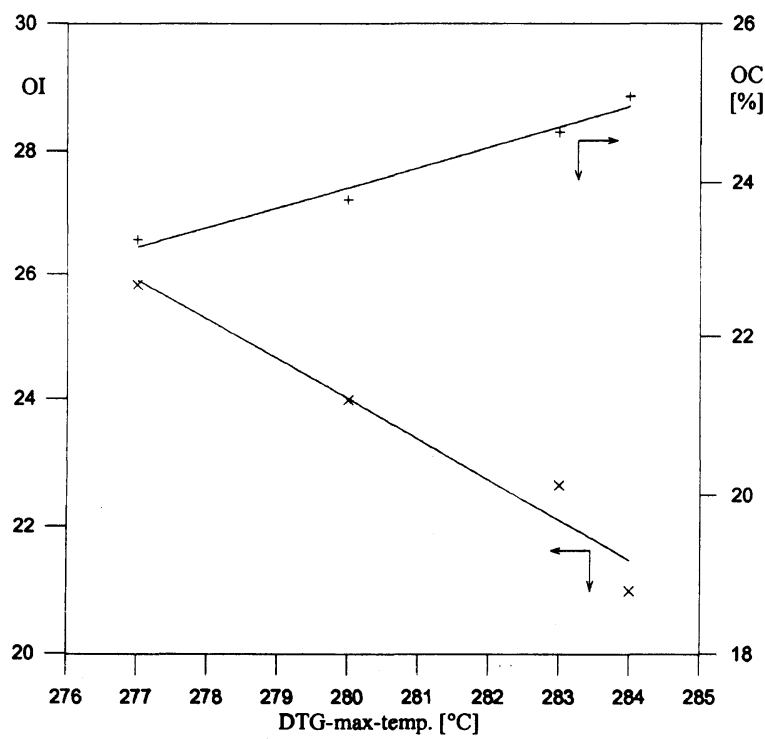

Figure 8. OI and OC vs. DTG-max-temperature.
(Figure 7) and DTG-max-temperature (Figure 8). The correlations are as follows:

$$
\begin{aligned}
& \mathrm{OI}=0.040\left(\mathrm{IDT}\left[{ }^{\circ} \mathrm{C}\right]\right)+20.440 \\
& \mathrm{OI}=0.009\left(T_{30 \%}\left[{ }^{\circ} \mathrm{C}\right]\right)+25.848 \\
& \mathrm{OI}=0.323\left(\mathrm{DTG}-\max \text {-temp. }\left[{ }^{\circ} \mathrm{C}\right]\right)-62.942 \\
& \mathrm{OC}=-0.060\left(\mathrm{IDT}\left[{ }^{\circ} \mathrm{C}\right]\right)+31.745 \\
& \mathrm{OC}=-0.067\left(T_{30 \%}\left[{ }^{\circ} \mathrm{C}\right]\right)+39.703 \\
& \mathrm{OC}=-0.508\left(\mathrm{DTG}-\max \text {-temp. }\left[{ }^{\circ} \mathrm{C}\right]\right)+163.443
\end{aligned}
$$

These expressions are valid for MDI and 3-chloro1,2-propanediol based polyurethanes, investigated under definite experimental conditions.

The flammability suppressant action of chlor-derivative should be considered in three main approaches towards polymer combustion, namely vapor phase, condensed phase, and miscallaneous. The possibility of distinguishing these mechanisms is offered by the TGA method. The amount of char residue indicates that there is not only one definite mechanism, although chlorinated paraffins and chlorocycloaliphatics were found to act primarily by a vapor-phase flame inhibition mechanisms, characterized as follows ${ }^{12,13}$ :

(i) flame-retardant element lost from the substrate;

(ii) flame inhibition insensitive to substrate structure;

(iii) flame retardance sensitive to oxidant, e.g., $\mathrm{O}_{2}$ or $\mathrm{N}_{2} \mathrm{O}$;

(iv) flame retardant does not change the compositions or amounts of volatiles.

The overall flammability mechanism (the rate-controlling process) results from the chemical structure of modificated polyurethane. For the samples studied there are three main char residue values $-32,37-39$, and $42-44 \%$ showing that different mechanisms are ratecontrolling or that external factors influence the whole process.

\section{CONCLUSIONS}

Thermogravimetric analysis may be used for flammability prediction of modificated polyurethanes based on MDI and 3-chloro-1,2-propanediol. There are correlations between oxygen index (or oxygen content) and several thermal parameters, such as the initial decomposition temperature, temperature of $30 \%$ mass loss and DTG-max-temperature. It is thus possible to evaluate flammability from thermogravimetric data alone. To gain a deeper understanding of the mechanism of degradation, TGA with FT-IR was used. Decomposition occurs mainly via the formation of $\mathrm{CO}_{2}$. DSC data give information on material behaviour prior to and during degradation, but determination of the thermal parameters is rather difficult.

Acknowledgements. The author is grateful to the "Foundation for Polish Science" for financial support.

\section{REFERENCES}

1. A. Tewarson and R. F. Pion, Combust. Flame, 26, 85 (1976).

2. ASTM E1354-90 (1990).

3. ASTM D2863-87 (1987). 
4. D. W. Van Krevelen, Polymer, 16, 615 (1975).

5. T. D. Gracik and G. L. Long, Thermochim. Acta, 212, 163 (1992).

6. K. Pielichowski, J. Pielichowski, H. Altenburg, and M. Wiegmann, Angew. Makromol. Chem., 224, 89 (1995).

7. K. Pielichowski, J. Pielichowski, H. Altenburg, and H.-J. Balloff, Thermochim. Acta, 284, 419 (1996).

8. W. Schoeniger, Mikrochim. Acta, 74 (1954).

9. N. S. Allen and M. Edge, "Fundamentals of Polymer Degradation and Stabilisation," Elsevier Applied Science, London, 1992.

10. J. Pysiak and B. Pacewska, Thermochim. Acta, 200, 205 (1994).

11. W. P. Yang, C. W. Macosko, and S. T. Wellinghof, Polymer, 27, 1235 (1986)

12. E. A. Turi, Ed., "Thermal Characterization of Polymeric Materials," Academic Press, New York, N. Y., 1981.

13. J. W. Hastie and G. D. Blue, Org. Coat. Plast. Chem., 33, 484 (1973). 